\title{
Change Management Perceptions in Portuguese Hospital Institutions Through ITIL
}

Pedro Fernandes Anunciação, College of Business Administration, Polytechnic Institute of Setúbal, Portugal

(iD) https://orcid.org/0000-0001-7116-5249

Nuno Santos Geada, College of Business Administration, Polytechnic Institute of Setúbal, Portugal

(iD) https://orcid.org/0000-0003-3755-0711

\begin{abstract}
Organizations function in complex, dynamic, and unpredictable environments. Implementing changes must therefore be well planned, managed, and evaluated as such ongoing efforts link organizational performance to peer competitiveness and sustainability. In an era challenged with technological innovations, it is crucial to understand how new changes can leverage traditional methodologies and services supported by information and technology systems. As information-intensive organizations such as hospitals are highly dependent on changing information and technological systems, this understanding is key to evolve next-generation hospitals. Specifically, this study analyzes how hospital managers in Portugal relate change to information systems' management based on information technology infrastructure library methodology. The relationship between change and information technologies services is not sufficiently clarified and constitutes an excellent opportunity to increase knowledge in the field of information systems.
\end{abstract}

\section{KEYWORDS}

Change Management (CM), Healthcare Organizations (HCOs), Hospital Institutions, Information Systems and Technologies (IST), Information Technology Infrastructure Library (ITIL)

\section{INTRODUCTION}

Information systems and technologies (IST) play an increasingly critical role in organizations vis-àvis their established relationships with the environment. Predicting future economic activities and societal trends is based on shifting information and IST are responsible for its availability and quality. Information is key to unveiling economic and social analytics and is a central resource to uncovering the relationship among different stakeholders (Oliveira \& Anunciação, 2019). The handling of information and the generation of knowledge are dependent on IST for the organizational processes' management and activities and to support customer needs.

Over the years, organizations, particularly those in the health sector, have become informationintensive organizations and/or pluralistic organizations (Asad Mir, Rezania \& Baker, 2020). They centralize their IST as it is difficult, if not impossible, for hospitals to provide health care services to people without accessing their medical records, to develop new knowledge without capturing the history logs of different patients or to prescribe new treatments without analyzing previously

DOI: 10.4018/IJHISI.20211001.oa18

This article published as an Open Access article distributed under the terms of the Creative Commons Attribution License (http://creativecommons.org/licenses/by/4.0/) which permits unrestricted use, distribution, and production in any medium, provided the author of the original work and original publication source are properly credited. 
administered medication and outcomes. Altogether, this calls for an awareness of the prominence of the information provided by IST to the managers of these institutions with a growth sensitivity to the significance of IST which has led organizations to look at them as driving forces of organizational performance in terms of the quality of services delivered (Garrido, Kristensen, Nielsen, \& Busse, 2008).

Healthcare organizations (HCOs) such as hospitals are burdened with data-intensive activities that generate information and consolidate knowledge. Information and knowledge are often viewed as critical assets, resources of driving actions and evidence to make decisions. While information technologies (IT) have led innovations in HCOs, chiefly, at the level of specialized activities developed, such as diagnosis and exams, the specificity of almost all such activities, which highlights the importance of proper management, is still supported technically by IT. For innovation to thrive, HCOs need to integrate functional, informational and technological requirements, adjusting to the dynamics and modus operandi of the operation and the relationship with the new technological requirements vis-a-vis evolving market opportunities. In this context, change management (CM) evolves (e.g., Ammenwerth, Iller, \& Mahler, 2006). It is this permanent strand of change that must be matched with a process, or processes, that make it possible to monitor the evolution of organizational activity and consolidate the transition from an existing reality to a new one with increased efficiencies and effectiveness (e.g., Weick K., 2000; Weick \& Quinn, 1999).

In this paper, the overarching goal is to show that CM is key to shaping the economic organizations' performance. Here, we adopt Information Technology Infrastructure Library (ITIL) as an internationally known methodology to elicit perceptions of IST managers in Portugal. Importantly, the IST services are crucial to operate and support organizational activities and the ITIL methodology enables these managers to facilitate service management via well received practices so as to adjust the services provided by IT to business core objectives (Cartlidge, et al., 2007).

The rest of this paper is organized as follows. The next section, Section 2, overviews the extant $\mathrm{CM}$ literature. Section 3 highlights the relation between ITIL and IST change phenomenon whereas Section 4 shifts focus to the health sector, detailing the case of managing HCOs in Portugal. In Section 5 , the two-stage investigation of managerial perceptions via the ITIL methodology is described while Section 6 presents the study results. Section 7 then follows with an analysis of the results with a model proposal that best encapsulates the study results provided in Section 8. Finally, Section 9 provides summative insights and concluding remarks.

\section{CHANGE MANAGEMENT (CM)}

According to Chiavenato, (2010), change means transiting from one state to another, totally or partially different. The transition or change from one situation to a different one or, simply, "doing things differently" (Robbins, 2010), only makes sense in a framework of peer competitiveness and sustainability, for example, adding an economic value to the organization, adapting to the existing legal framework and investing in innovation and continuous improvement vis-à-vis shifting environments. Change should not be an end to itself (Bériot, 1997), but it should be an opportunity to improve a system by changing its state. New laws or regulations, new technologies and market satisfaction (Hernandez \& Caldas, 2001) demand changes to make economic organizations more competitive and adjusted to the realities of the market (Camara, 2005). This requires a change and it must be managed (Patterson \& Wigham 2019). The only way for organizations to achieve the objectives associated to an evolving change is via management and it must be developed and controlled vis-à-vis projects. This means change is always specific and should not be standardized. However, solutions to most everyday challenges do not require revolutionary change (Gersick, 2020). Some authors believe in a simultaneous adoption of different approaches: episodic v. radical, continuous v. incremental (Balogun \& Haley, 2004), and planned v. emerging (Cunha \& Rego, 2002). 
Notwithstanding the differing change approach being adopted, managers must attend to the specificity of the requirement of change. For example, episodic change is geared towards unique and large-scale events, separated in time (e.g., Luecke, 2003; Weick \& Quinn, 1999) whereas continuous change is directed towards small changes, resulting from the organization's continuous adaptation to the shifting environment (e.g., Luecke, 2003; Weick \& Quinn, 1999). Conversely, radical change is appropriate for very profound changes, affecting the organization as a whole (e.g., Nadler \& Tushman, 1990) while incremental change is suited for shallow changes, involving only a part of the organization (e.g., Nadler \& Tushman, 1990). Finally, planned change is directed towards processes controlled and managed via a sequential set of steps, in order to move the organization from a present state to a desired future state (e.g., Porras \& Robertson, 1992; Lippit, Watson \& Westley, 1958; Lewin, 1951) whereas emerging change corresponds to a continuous process of adaptation to a complex and unpredictable environment (e.g., Luecke, 2003; Kotter, 1995,1996; Kanter et al., 1992; Pettigrew \& Whipp, 1991).

Oftentimes, management is responsible for leading the change and obtaining the desired results. Two different approaches may be highlighted which are at the core of the principal models of organizational change: planned change and emerging change (e.g., Todnem R., 2005; Kezar, 2001). Planned change, according to Lewin (1951), means that the systems are "frozen" before any change can be made; briefly, the systems are "shut down" prior to implementing operating principles with the intended changes being introduced. The proposed model of «Unfreeze-Move-Refreeze» comprises three distinct stages:

- $\quad$ defrost from the present level, Unfreeze;

- move to a new level, the Move, through which it is supposed to apply the changes and obtain stakeholders' acceptance of these changes; and,

- put the system in the desired state, Refreeze, with the changes introduced, reflecting the organizational acceptance and expressing a new functioning reality.

The authors strongly endorse this approach to change and consider it truly important to understand the associated processes by identifying the states the organization must achieve. Bullock \& Batten (1985) propose an approach based on a roadmap, considering three central aspects: the organizational context (reason for the change), the content (scope of the change) and the process (operationalizing the change). Emerging change suggests guiding models for implementing change. Specifically, some researchers have proposed a more comprehensive model for the assessment of the various associated dimensions, facilitating the management of uncertainty and turning organizations into open learning systems via diagnosis, vision and objectives, enhancement of human aspects, leadership, communication, monitoring, organizational culture and the consolidation of change (e.g., Mento, Jones \& Dirndorfer, 2002; Galpin T., 2000). These elements are part of a model that must be adjusted to the specificity of the change and the organizational reality, considering the fundamental dimensions for the success of any change process (Turner, Hallencreutz \& Haley, 2009). The importance of applying a holistic approach to such change management models should be further emphasized.

\section{ITIL \& IST CHANGE}

The economic organizations' performance rationalizes an investigation of CM. Some models, such as the open group architecture framework (TOGAF), have a specific and dedicated phase for managing change, unlike many other models that have change management processes embedded in multiple phases or stages, which further challenge the managers' ability to articulate such needed processes. More specifically, ITIL, an internationally known methodology adopted by many IST managers, is chosen in the current study reported herein.

As shown in Figure 1, ITIL comprises the following phases (Cartlidge, et al., 2007): 


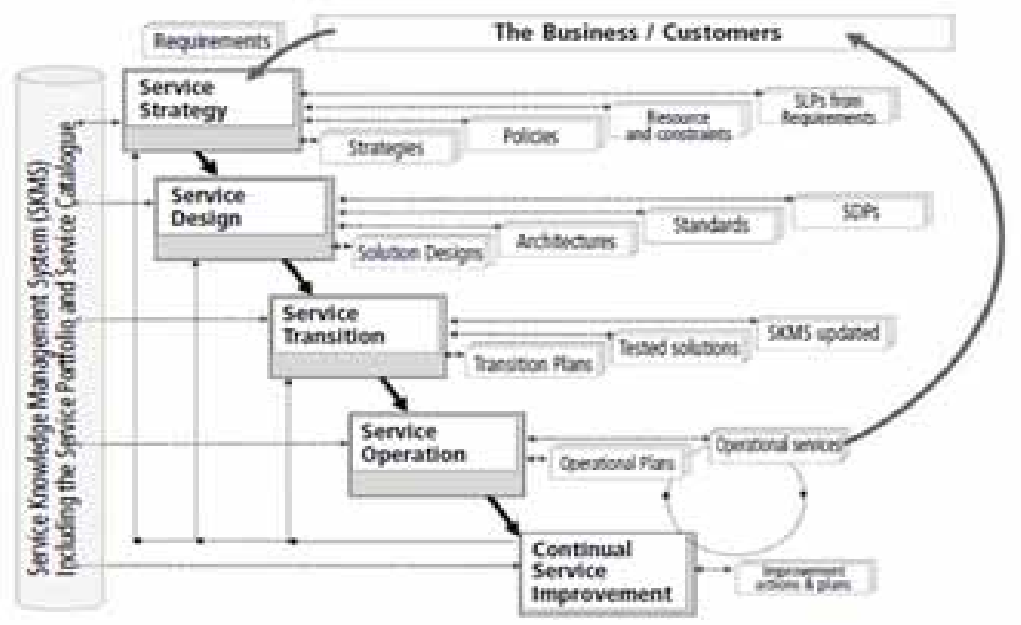

- $\quad$ Service Strategy - definition of business requirements and needs;

- Service Design - definition of the solution to be adopted;

- Service Transition - relates to the management of the changes made;

- Service Operation - ensures that services are managed based on SLAs (Service Level Agreement);

- Continuous Service Improvement - maintains the constant improvement of services based on the PDCA (Plan, Do, Check, Act) cycle.

As a widely accepted international methodology, ITIL offers benefits, including (a) an improvement of IST services and risk management v. business needs; (b) an increase in the levels of flexibility of services and the consistency and predictability of processes; (c) better efficiency in the delivery of services; (d) a standardized measurement of services and processes; (e) the optimization of customer experience; and (f) the adoption of a common and universal language. Among others, ITIL sets good practices for IST management and provides superior efficiency and effectiveness in organizational functioning.

Notwithstanding, these aforementioned benefits are possible only if the IST and organizational managers understand that ITIL, as a methodology for service management, requires adjustments in IST services and organizational functioning. By considering all the ITIL phases, it is possible to verify that the transition phase was the stage that best expressed the transition challenge as it presupposes a change to a new status quo and requires steps to be taken by management in order to achieve the defined objectives.

Considering CM in the phase of service transition provides guidance to management about the complexity related to new services and compliance with IST processes. This avoids the undesirable consequences of a bad transition as some variables that may be present in this stage of ITIL are transition planning, change management, service management, configuration assets, validation and testing. CM, in the scope of ITIL, is related to the value of the service to be provided, depending on the opportunities for continuous improvement to be incorporated. For this reason, these improvements should be monitored in Service Operation, the next phase, as it is here that guidance should be provided 
Table 1. List of Change Management phases versus ITIL phases

\begin{tabular}{|l|l|}
\hline \multicolumn{1}{|c|}{ ITIL (Phases) } & \multicolumn{1}{c|}{ Change } \\
\cline { 1 - 1 } Service Strategy (definition of business requirements and needs) & \multirow{2}{*}{ Preparation } \\
\cline { 1 - 1 } Service Design (definition of the solution to be adopted) & \\
\cline { 1 - 2 } Service Transition (relates to the management of changes made) & Implementation \\
\cline { 1 - 2 } $\begin{array}{l}\text { Service Operation (ensures that services are managed based on the Level } \\
\text { Agreements defined) }\end{array}$ & Enforcing \\
\cline { 1 - 2 } $\begin{array}{l}\text { Continual Service Improvement (maintains the constant improvement of services } \\
\text { based on the PDCA cycle (Plan. Do, Check, Act) }\end{array}$ & \\
\hline
\end{tabular}

on the validity of the change and the stability of the service itself. Nonetheless, it is possible to assume that change is present in all ITIL phases, from the planning to the operation phase, as shown in Table 1.

A key question in analyzing the extent to which the adoption and practice of ITIL, as widely endorsed by many economic organizations, will affect CM in a conscious and pragmatic way is the need to identify the group of organizations to be studied. Here, we center the analysis in hospitals due to the complexity of their characteristics, the role of technological services and the performance of their activities, that will offer support to an interesting investigation.

\section{THE HEALTH SECTOR}

Over the last two decades, health care has been a primary target of political and governmental changes in many countries (e.g., Mikkola \& Stormi, 2020; Saltman \& Duran, 2016; Cox \& Hassard, 2010; Thurlow \& Mills, 2009). In Portugal, the health sector is complex and sensitive to IST activities. The functioning of health institutions is based on different types, formats, and origins of information and informatics, used by a variety of stakeholders (health professionals and others), with differing expectations and interests. In fact, the sources of information in hospital units are widely distributed, heterogeneous, vast, complex and integrated; that is, it draws on important clinical informatics and information systems in support of hospital processes (DGS, 2012). In this context, IST plays a critical role in the development of clinical activities and processes and in support of health professionals' decisions as, most of the time, information is used in real time.

Even so, resistance to change will affect the quality of services provided. Considering the fact that the quality of service is one of the main critical factors of healthcare services, General Service of Portuguese Health (DGS, 2012) consider that service quality to be one of the main critical factors of health services. Owing to rapid IT innovations, managing change in healthcare institutions must not only consider the quality of services and the rearrangement of administrative processes, it must also encompass all organizational resources. Health managers have to consider the different levels of complexities, and they should also pay special attention to people's mentality, as, in most cases, the greatest entropy in the application of change is triggered by actors (e.g., Rance, et al 2011; Lapoite \& Rivard, 2006). Such change(s) must correspond to technical processes (Craft, Warnock \& Heltai, 2013 ) in the different domains, including specific functional, technological and sociological aspects. Innovation must be assimilated from the strategic level. However, at this level, there is often a need to rethink and redesign the organizational logic and dynamics to improve its economic performance, the adequacy of communication with the market and the differentiation of the commercial offer, which presupposes change (Geada \& Anunciação, 2019).

The extraordinary impacts of social events, such as the recent Pandemic Covid-19, tested the response capacity of all organizational systems to urgent, high-risk health situations. The need for online information and reliance of health professionals and government members on this information 
to act and decide promptly consolidated the crucial role of IST in the normal functioning of health institutions and society. One of the critical elements of the IST support to organizational activities corresponds to the technological services' availability. As the IST services can be understood as the set of specialized organizational skills that provide value to IST customers in the form of services which must guarantee technological support to the organizational needs and strategic changes, the focus of our study on IT infrastructure, applications, operation of technological and governance processes and it's management is fully warranted. IST services underline the motivation to initiate this investigation and the methodology of ITIL is considered the best instrument to analyze and understand the relationship between IST services and CM. Moreover, the study of Portuguese hospitals also seemed to provide a good case study to achieve the state-of-the-art.

In Portugal, rising healthcare costs has posed questions related to the sustainability of hospital systems, including IST, and the need to make hospitals systems more efficient, without affecting to their quality and performance. This need was behind the government's new management policies in health care with the aim of reforming the sector and improving efficiency levels and effectiveness via the IST (e.g., Alves, 2014; Fernandes, 2014; Harfouche, 2008). Within the health systems, hospitals constitute structural units of the Portuguese National Health System and they are central institutions of social great value for the provision of healthcare services, assuming a reference position in the national health system (Vaz, 2010). Owing to their relevance, health policies have been given special attention to hospitals to make them profitable social services whilst still maintaining quality. In order to do this, it requires the adoption of innovative management models that allow the achievement of good results (e.g., Casella, 2009; Vaz, 2010). This constitutes a big management challenge: the reach of health social integration and cohesion, generating well-being (Health, 2018), and economic and financial sustainability that will inevitably go through the IST and via the currently envisioned e-Health 4.0.

As a class of economic and social organizations, healthcare organizations (HCOs), v. other types of organizations, is extremely complex and CM is particularly hard. HCOs face constant challenges that will impact on human lives; therefore, the change requires special attention from health managers and a technical analysis in order to maintain the quality and performance expected by the specificity of the respective activities (e.g., Campbell, 2008; Agyeman-Budu \& Welvaert, 2006; McAuliffe \& Vaerenbergh, 2006; Drucker, 1993).

Notably, some of the associated challenges from HCOs result from the below factors (DGS, 2012; Rego \& Nunes, 2010; Golden, 2006; DGS, 2004; Iles \& Sutherland, 2001; Applebaum \& Wohl, 2000; Church, Siegal, Javitch, Waclawski \& Burke, 1996):

- $\quad$ the existence of multiple professional functions, corresponding to different specialties and different areas of knowledge;

- professional and knowledge convergence (e.g., medicine, nursing, pharmacy, and more);

- interaction with different stakeholders (e.g., users, government, suppliers, professional orders, unions, and others) with different interests and perspectives;

- interdependence of teams, whose performance depends on the collaboration between the respective members;

- the power and autonomy of some professionals, whose decisions and performance influence the quality of service provision and user satisfaction;

- constant changes in the environment, namely at the level of society, the market, the government, technologies, values, and other aspects;

- the need to monitor major technological changes in the health area, in terms of processes, diagnoses, treatments and IS;

- $\quad$ increasing demands from user groups, with the same needs and expectations, also increasingly informed;

- requirements of the government and regulatory authorities regarding the performance and quality of the health services provided; 
- investors' requirements regarding performance and results;

- $\quad$ lack of time / opportunity to manage change processes in health organizations;

- past change experiences with unforeseen and unintended consequences, giving rise to resistance to new change initiatives.

All these noted factors interfacing with technological innovations require structural, organizational, functional and informational adaptations in the hospital operations. Managers and healthcare administrators must remain alert and ready to anticipate the need for change, emphasizing the technological innovation impact on hospital activities, using methodologies to achieve their objectives.

\section{STUDY OBJECTIVES AND METHODOLOGY}

As many management instruments and methodologies do not have, in their methodological procedures, a phase dedicated to CM, the main objective of this study is to analyze health managers' perception about the importance of CM vis-à-vis ITIL. Although it is universally accepted that the CM theme is generally considered critical in the IST, it is important to study the level of adoption as well of CM practices in IST service management.

This study is undertaken in the main Portuguese hospitals, which have a complex nature of activities and processes, heavy organizational structures, diversity of knowledge and skills among the different professionals and a preponderance of the IST in the development of the respective activities. Therefore, it is scientific and technically relevant as well as appropriate to analyze the adoption of CM practices associated to IST service management.

We structure the investigation in two stages: in the first stage, we analyze the scope and depth of scientific investigation in this area to assess the relevance and the opportunity of the study. In the second stage, we analyze the hospitals managers' perception of the relevance of CM based on the ITIL methodology. In this case, the authors try to only analyze the IST managers' awareness of the management of IST services. The current study is conducted via an inquiry addressed to the person responsible for management (top management) and IST (middle management). This inquiry is built with the objective of analyzing the knowledge level of the ITIL methodology, its adoption in the processes of development and implementation of new services, related with CM.

The survey questionnaire is structured in five blocks:

- Sample characterization - demographics and other information about the respondents, including the area/function performed, the hierarchical level in the organization, professional functions and geographical location;

- IST and change projects - drivers of change projects, management needs and the relationship between change and competitiveness. Questions about the practices of the respective organizations are also included;

- $\quad$ ITIL methodology (professional and organization knowledge) - perception of which phase or phases of ITIL methodology that would induce change;

- Relevant CM dimensions - the identification of main principal dimensions to consider in CM;

- Roadmap for change - the relation between the dimensions and ITIL phases to identify a roadmap for $\mathrm{CM}$.

As for the classification of the relevance of the proposed dimensions, the methodology followed in the survey is based on a 5-level Likert scale as follows:

Capítulo 3 
- 1 - Irrelevant / Strongly disagree - irrelevance of the theme or lack of sensitivity to it and to the need for change management in the organizational context;

- $\quad 2$ - Slightly (little) relevant / Disagree - weak sensitivity to the topic and weak relevance given the opportunities for change associated with ITIL;

- $\quad 3$ - Indifferent / I do not agree / nor disagree - indifference as to the relevance of ITIL and change, as well as the relationship between the two, respectively;

- 4-Relevant / I agree - relevance to the theme and awareness of its importance in changing value generation, but with weak strategic accuracy;

- 5 - Very relevant / I totally agree - high strategic accuracy regarding the opportunity for change as an inducing factor in the generation of value;

- DNK/DNA - does not know / does not answer - ignorance or lack of interest in the topic and in the respective organizational impacts.

Through this scale, it is also possible to assess the importance given by respondents to each of the domains and dimensions presented, having established the relationship as noted.

\section{STUDY RESULTS}

In term of the first study stage, after analyzing the data related to CM and ITIL in the health sector (hospitals), as can be seen in Table 1, the authors found that there is a high potential for the development of scientific knowledge related to the understanding of managing change in IST services.

Until now, there is scanty research that analyzes the relationship between change and ITIL, namely factors underlying the impact of service management on organizational change. The management of IST services, especially in an information-intensive organization, requires effective CM models. This is the key purpose of this research. Research on the master topic of this study has been noted on the website «www.webofknowlegde.com». So, the criteria for filtering search was: «Change management information systems in public hospitals»; «all years»; and «SCI-EXPANDED, SSCI, A\&HCI, CPCI-S, CPCI-SSH, ESCI, CCR-EXPANDED, IC».

As shown in Figure 2, results obtained included two records (2013 (1) and 2019 (1)).

Under the topic of «Change Management and Information Systems in Portuguese public hospitals» and the criteria «all years» and «SCI-EXPANDED, SSCI, A\&HCI, CPCI-S, CPCI-SSH, ESCI, CCR-EXPANDED, IC», the results obtained comprised four records (2020 (1); 2018 (1) and 2015 (2)), as shown in Figure 3.

These results show the relevance of the study on $\mathrm{CM}$ in health sector and the possibility of building a model to aid managers.

In the second stage of the study, forty (40) inquiries have been dispatched with thirteen (13) responses received, which represents $32.5 \%$ of the universe of hospital institutions in Portugal. In the first set of questions, it is possible to verify that $23.1 \%$ of responses were given by the top management and $76.9 \%$ by intermediate managers responsible for the IST, as can be seen in Figure 4.

These results allow us to verify that the respondents assume the two most relevant roles for this study, because they represent the highest level of responsibility in the organization and also represent the IST area, with primary responsibility for changes associated with technological innovation and a specific knowledge of international methodologies. Regarding the degree of national coverage of the institutions analyzed, Figure 5 data show that $46.2 \%$ of the institutions are located in the center of Portugal, $30.8 \%$ are located in the North and $23.1 \%$ in the South.

On the second set of questions, the authors analyze, from a conceptual and pragmatic perspective, the relationship between IST and change. Regarding the conceptual perspective, the authors analyzed four (4) questions, namely, whether IST projects or whether the introduction of IST should have an associated change process; whether change projects should be managed; whether change management 
Figure 2. Research made of popularity of theme - change management hospitals digital innovation - computer science information systems

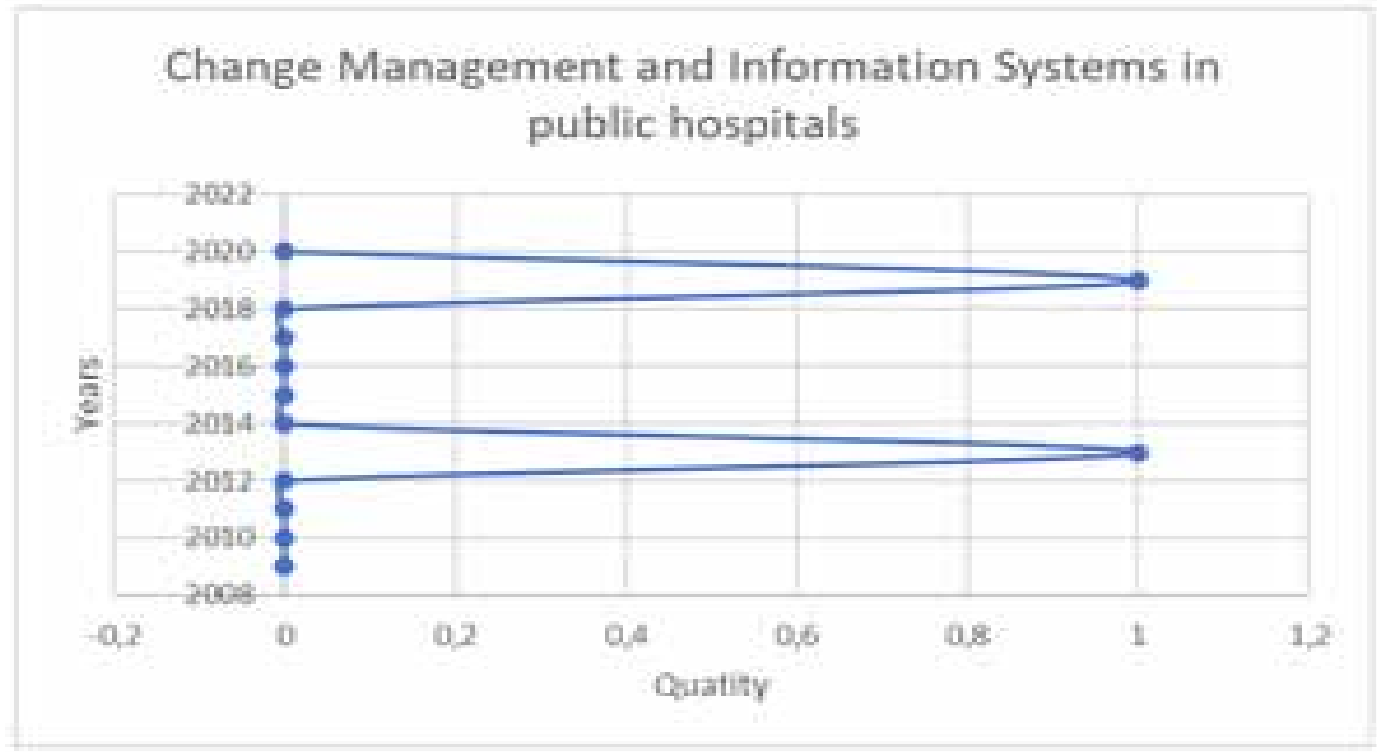

Figure 3. Research made of popularity of theme - Change Management and Information Systems in Portuguese public hospitals

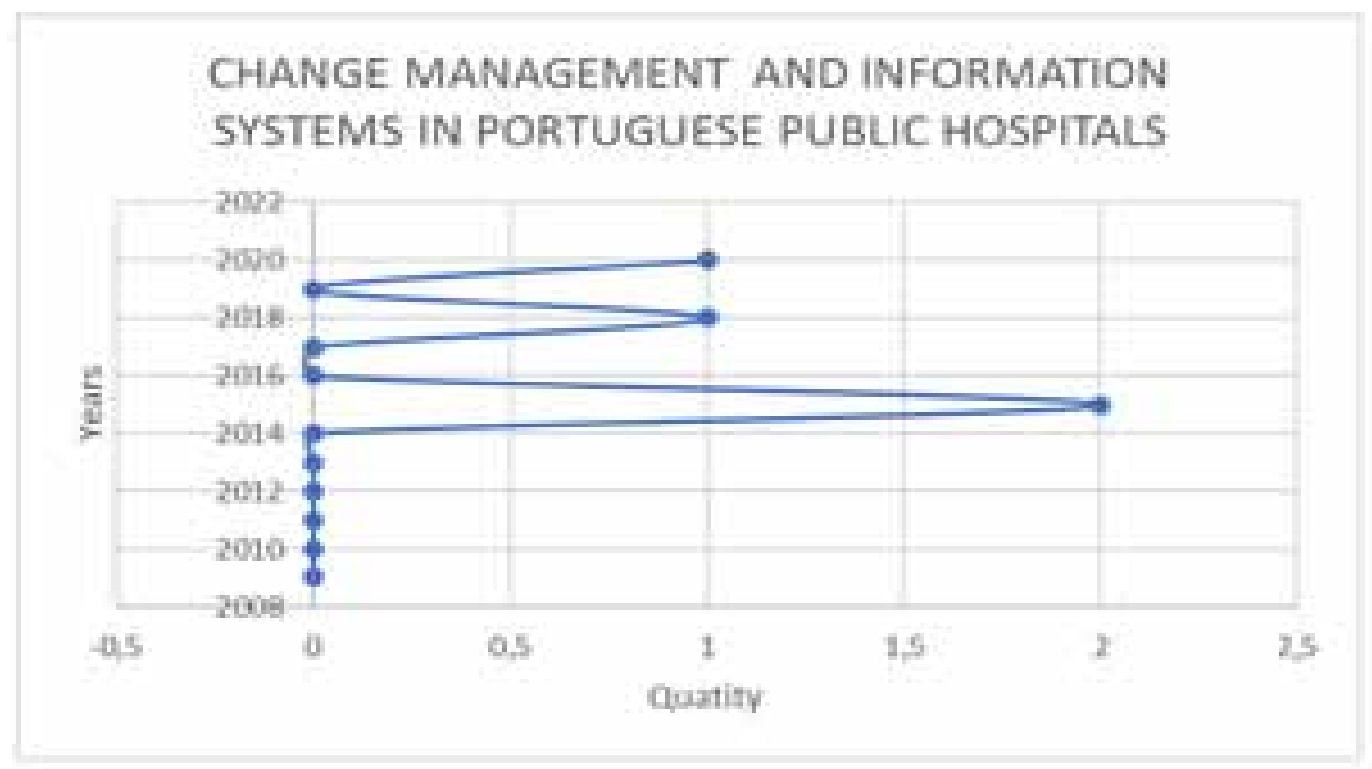


Figure 4. Area / Function performed

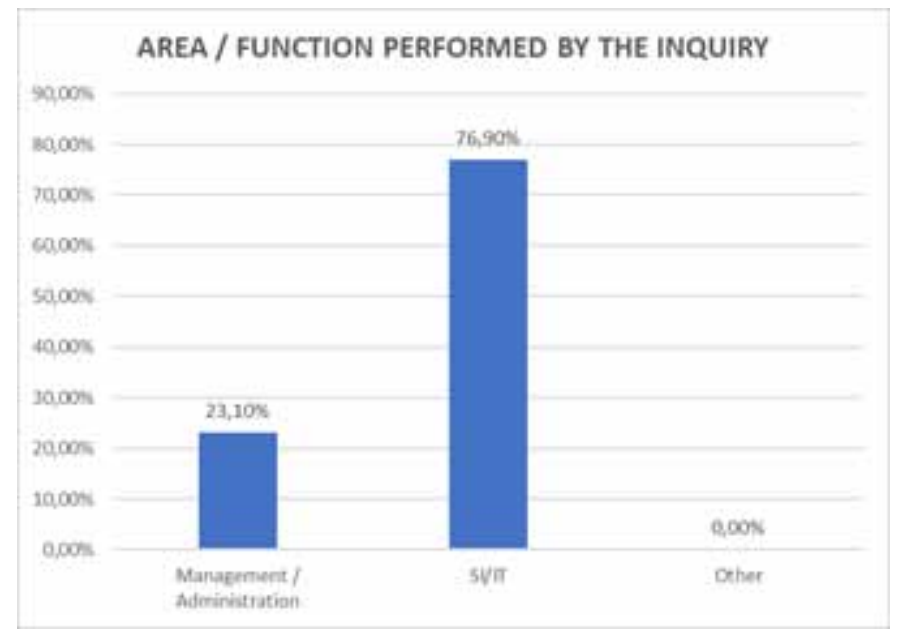

Figure 5. Geographic area of the institution

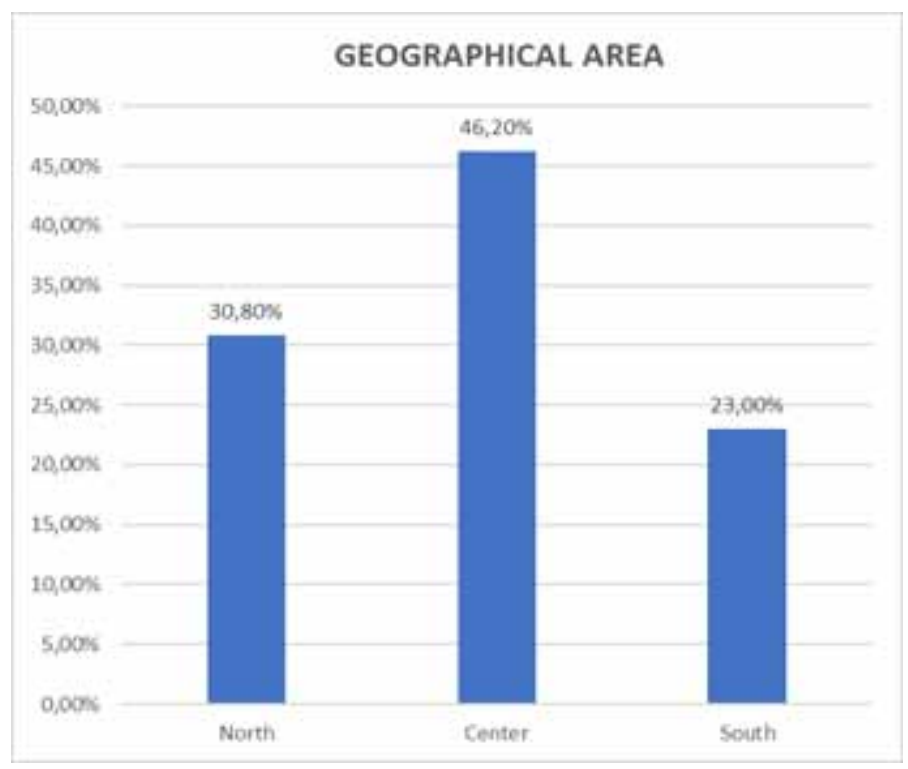

is essential for improving organizational performance and competitiveness; and, whether change projects should always be evaluated.

Results, as shown in Figure 6 verify that:

- $61.5 \%$ of respondents fully agree that IST projects or the introduction of technologies are associated with organizational adjustments and change processes, while $38.5 \%$ of respondents only agree. In this case, it is possible to verify the attribution of a lower level of relevance to the impacts mentioned; 


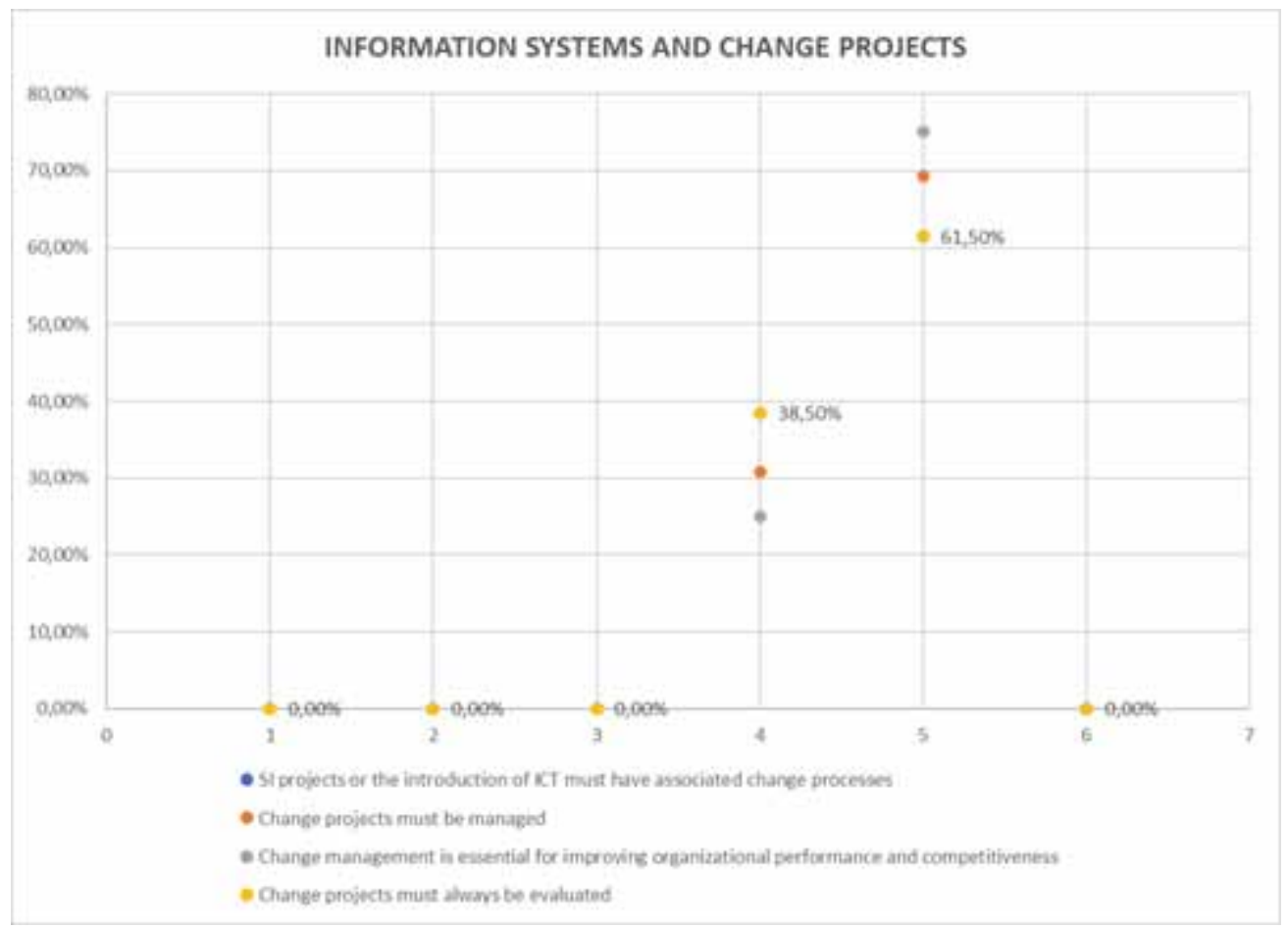

- $\quad 69.2 \%$ of professionals fully agree that IST projects should be managed, while $30.8 \%$ mention only an agreement;

- $\quad 75 \%$ of professionals consider that management is essential or very important for improving organizational performance and competitiveness, while $25 \%$ consider it to be relevant;

- $61.5 \%$ of respondents fully agree with the need for change projects evaluation, while $38.5 \%$ only agree.

From the main analysis of values obtained, it is evident that about $1 / 3$ of the respondents do not attribute the relevance that would be expected on the topics analyzed. This shows a contradictory professional attitude towards the associated bibliography, regarding the importance of CM and the relationship it has with organizations' performance.

Still in this block of analysis, the authors attempt to analyze the real adoption of CM practices in the respective organizations and question whether, as professionals, they develop CM projects when making investments or developments in IST; whether change projects are managed internally by the organization; whether the responsibility for CM projects lies with top management; and, whether change projects are always evaluated.

As shown in Figure 7, the following results are obtained:

- $33.3 \%$ always develop CM projects when making investments or developments in IST, 50\% sometimes develop projects and $16.7 \%$ of respondents show indifference to this topic. The absence of an expressive classification of this item in the maximum score leaves open the idea that the association between CM and investments, although real, does not always correspond to current practice. It is also ascertained that the results do not show a coherent practice relatively to the 
Figure 7. Management practices in Portuguese Health Organizational

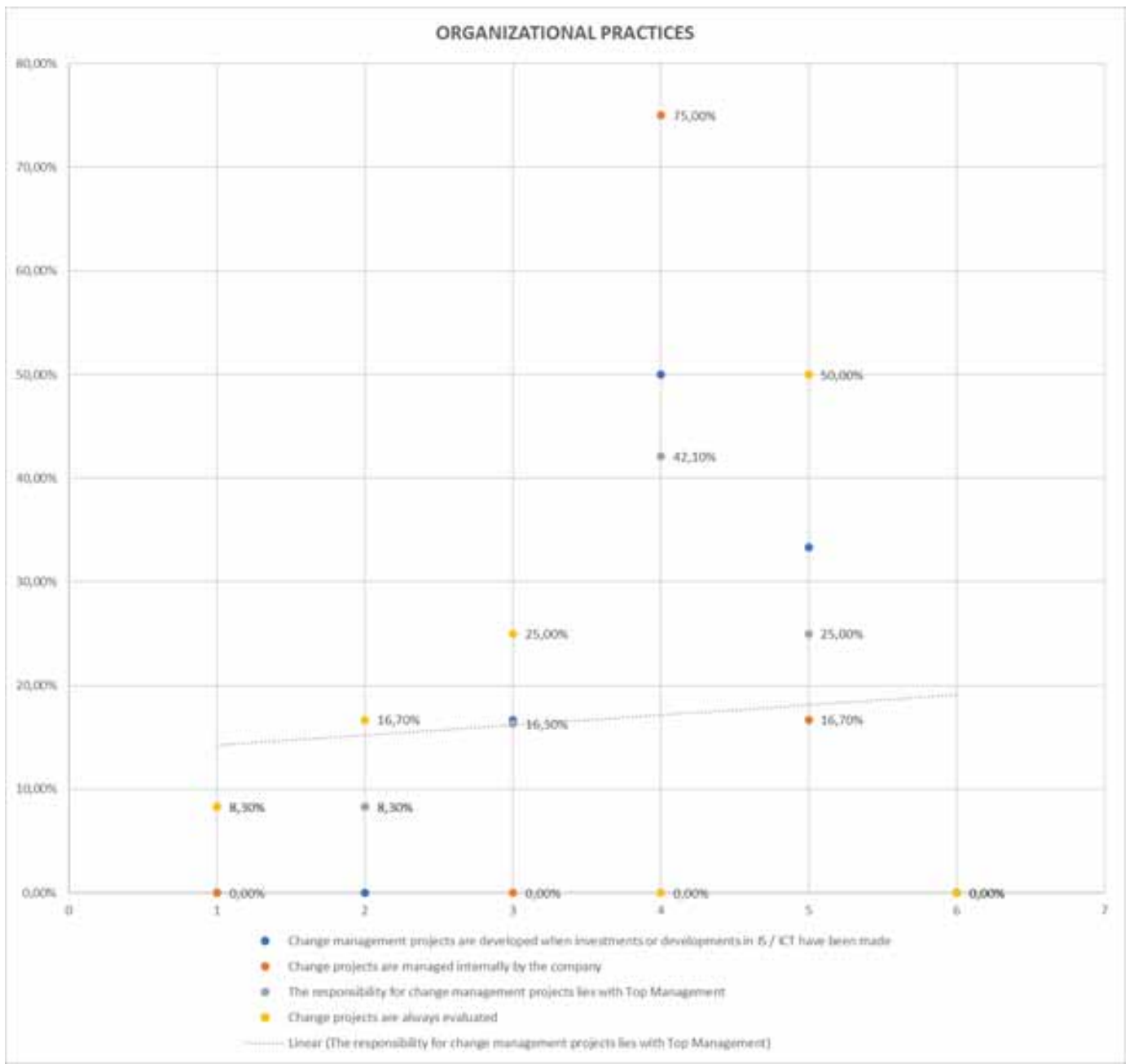

unequivocal statement that IST projects or the introduction of technologies must have associated change projects, as can be seen in the previous question;

- $16.7 \%$ of the respondents fully assume the internal management of the projects, while $75 \%$ agree with this statement, evidencing, by the assigned classification, that they participate in this management. The rest $(8.3 \%)$ disagree, which means that either there are no change projects associated with IS or they are not managed through internal skills;

- $16.3 \%$ of respondents are indifferent, neither agreeing nor disagreeing, regarding the role that top management should have in CM projects. This result may show a lack of knowledge or indifference to the relevance of the question. So, only $25 \%$ fully agree that these projects should be the responsibility of top management while $42.1 \%$ only agree, $8.3 \%$ disagree and $8.3 \%$ strongly disagree;

- $50 \%$ of respondents assume that change projects are always evaluated. The rest of respondents do not evaluate these initiatives (25\% show indifference, $16.7 \%$ disagree, and $8.3 \%$ disagree completely). 


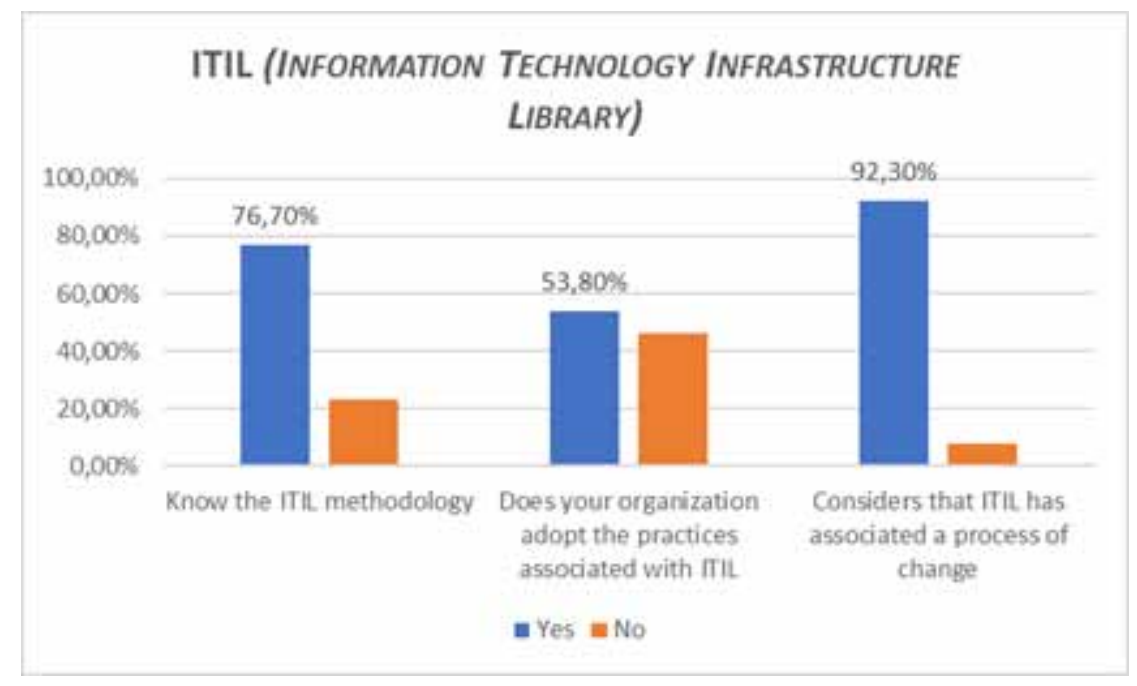

On the third set of questions, which aims to analyze the degree of knowledge of ITIL and associate the change with the phases of the respective methodology, it was analyzed, in the first part, the degree of knowledge of the ITIL methodology; the adoption of ITIL practices; and, in the second part, whether the respondents considered that ITIL associated it with a process of change. The obtained responses are given in Figure 8:

- most of the surveyed institutions claim to know the ITIL methodology (76.7\%); however, there are $23.3 \%$ that do not know;

- regarding the adoption and application of ITIL in the organizations, 53.8\% assume the adoption of ITIL practices. Yet, there are still $46.2 \%$ that do not;

- of the respondents who reported knowing ITIL, 92.3\% affirm and consider that ITIL is associated with a process of change, but only $7.7 \%$ disagree.

On the question asking which phases of ITIL should be included in the CM process, answers given in Figure 9 show that these are the "Service Design" and "Continuous Service Improvement" phases.

While all phases may be considered to be important for the CM process, the analysis showed that the phase "Service Design" (46.2\%) and "Service Operation" (30.8\%) are those in which change should be considered. Even so, it is interesting to note that the "Service Transition" phase, which in theory is the phase where the new service is being prepared, although relevant for most respondents, does not assume the expected expressiveness.

In term of the relevance of the traditionally most important dimensions in change projects, as shown in Figure 10, the answers show the «leadership» (77.0\%), «vision» (60.2\%), «knowledge» (53.8\%), «strategy» (69.2\%) and «planning and organization» (69.2\%). Interestingly, the assessment of the current situation and its relationship with the desired state, does not assume relevant significance, although this constitutes a foundational parameter in any process of change. Likewise, the relevance of the celebration is underestimated, contrary to the principles of culture and organizational cohesion.

Finally, looking at the relationship between ITIL and the stages of change, it is possible to verify, according to Figure 11, the respondents affirmed that, in the «Service Strategy», the most important items are «identification of the vision», «definition of commitment» and «definition of organizational capacities» and the least relevant is the «identification of leadership for change». 
Figure 9. Phases of ITIL where changes must be framed

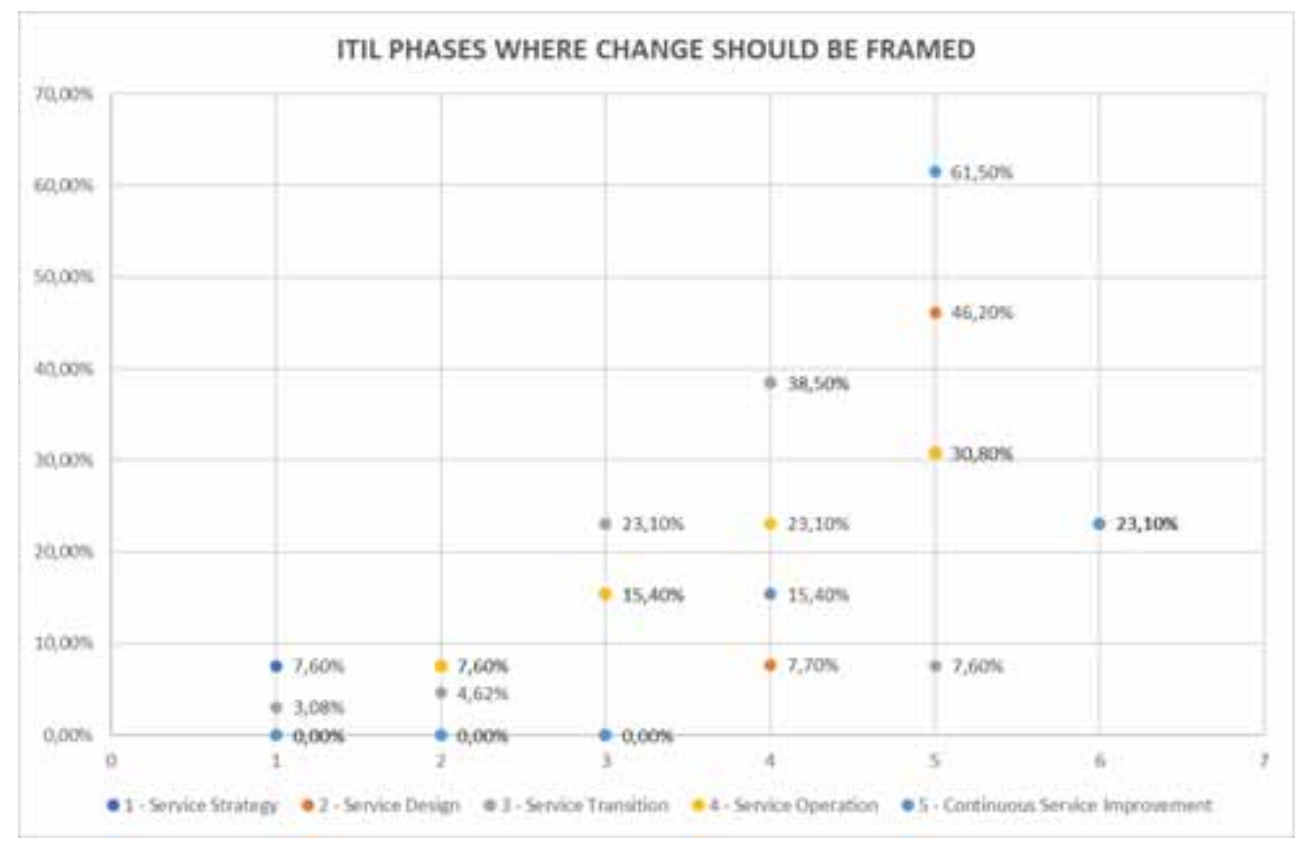

Figure 10. Change management dimensions

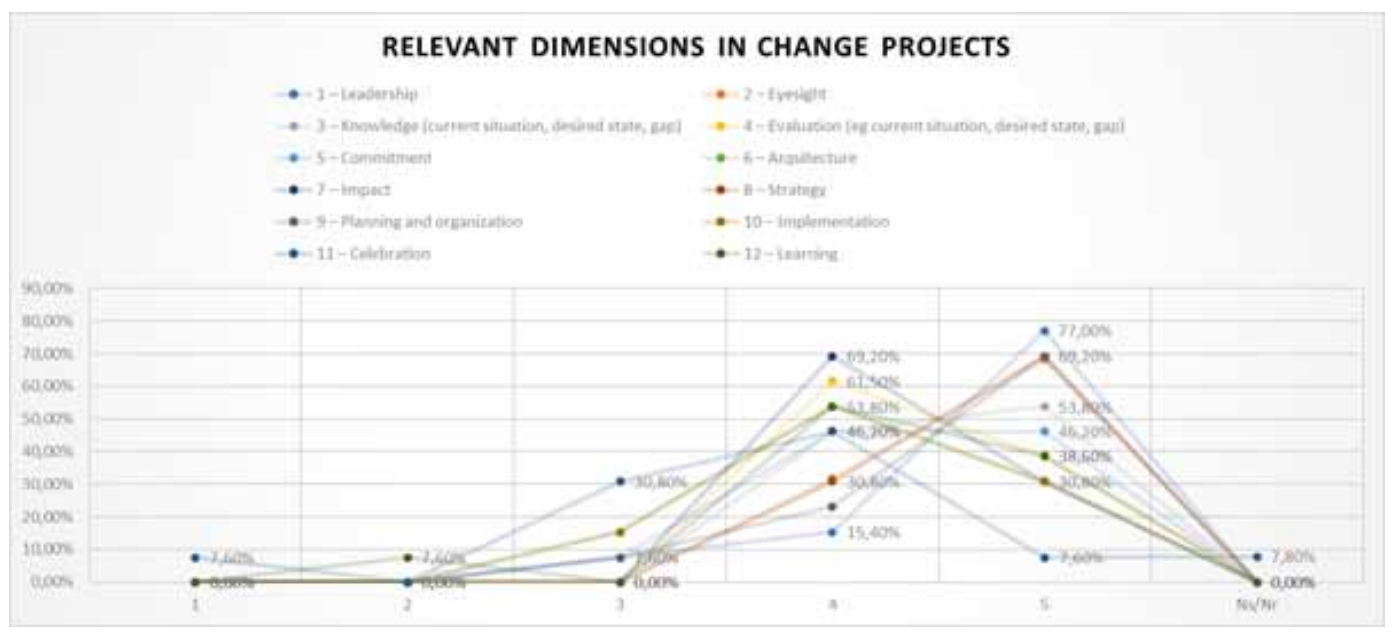

\section{ANALYSIS OF STUDY RESULTS}

The study results offer interesting insights, allowing one to envision the existence of a dichotomy between theory and practice; that is, it appears that while IST managers are generally aware of the technical and scientific principles associated with CM, only a few managers actually apply them. Hence, the main evidence for the analysis of the results is as follows: 


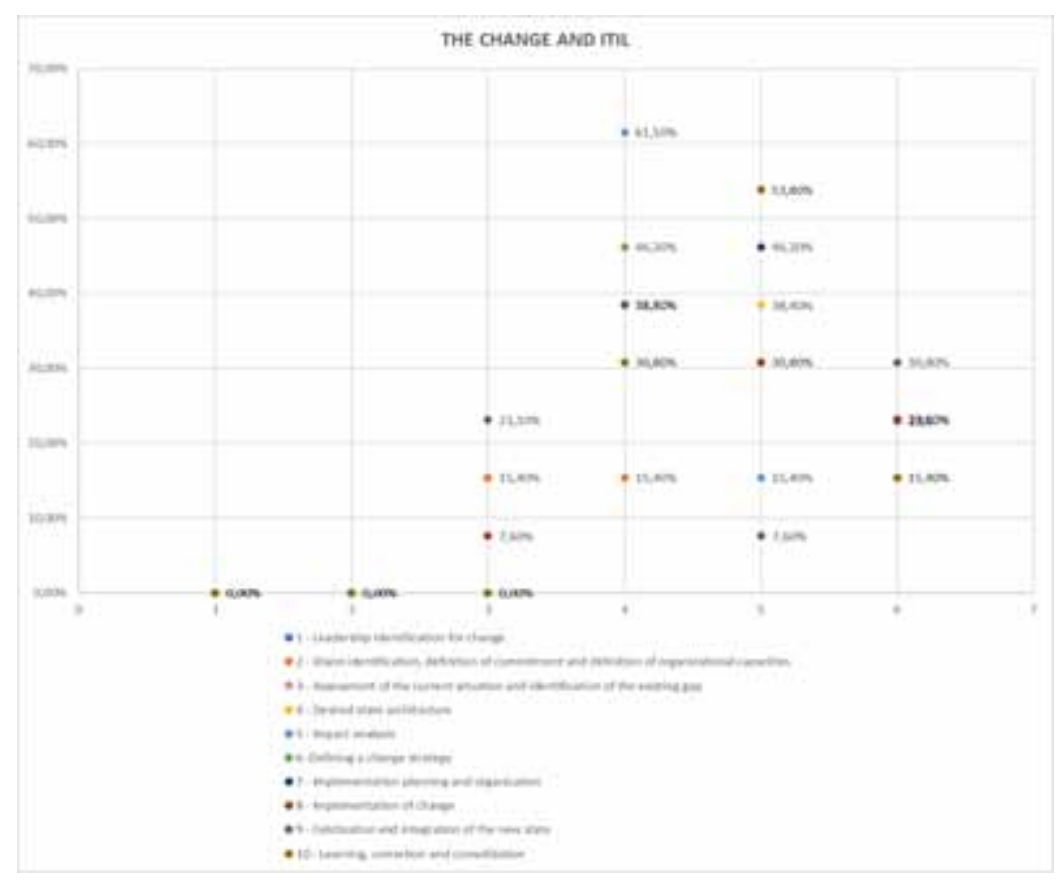

- Awareness among managers is visible on the interconnection between IST projects and CM. As provided in the literature, IST will have a significant impact on organizational dynamics; accordingly, any change recorded at this level relies on the development of activities for managing vis-à-vis the associated changes;

- $\mathrm{CM}$ is central to improving organizational performance and competitiveness. If the change is not properly planned nor managed, performance and competitiveness levels may be compromised;

- Just planning and managing the implicit change in IST investments is not enough. CM should be assessed. CM evaluation makes it possible to quantify the beneficial gains derived from that change.

Notably, these general principles assumed by IST managers in health institutions are not often reflected in managerial practices. The activities carried out in this field do not comply with the principles that they defend. The preponderance given to the principles loses relevance when asked if there are CM practices associated with IST investments, or if IST managers assume responsibility for the $\mathrm{CM}$ projects, or if $\mathrm{CM}$ activities are always evaluated. Unfortunately, it appears that the practices associated with $\mathrm{CM}$ do not generally reflect coherence.

Even then, regarding ITIL, some interesting results in the field of management should be emphasized. Given the nature of each of the ITIL phases, one would expect a greater preponderance of "transition" phase in answers as the closest phase of change. It is in that phase that IST managers preparing the release of a new service (the transition from «As-Is» to «To-Be»). Yet, the study results show that the remaining phases are even more relevant.

Finally, regarding the main dimensions considered in the CM, IST managers in health institutions consider that the most significant dimensions to be «leadership», «vision», «knowledge», «strategy» and «planning and organization». Other dimensions such as «evaluation» or «implementation» are not considered as relevant. All these facts mentioned are opportunities to develop future research directions to further clarify the answers and consolidate the scientific knowledge associated with CM. 


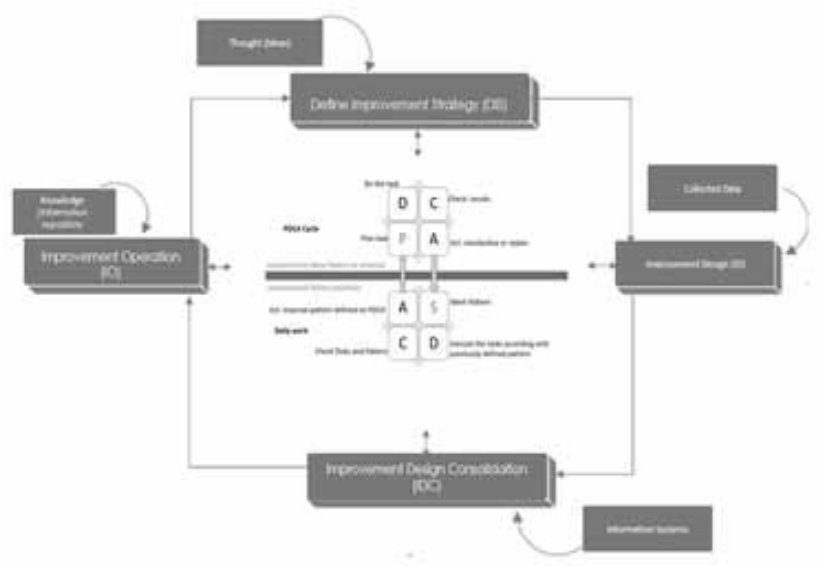

\section{MODEL PROPOSAL}

Based on the study results, especially the gaps between theoretical knowledge and professional practices, a model may now be proposed to facilitate a pragmatic adoption of CM.

The first CM stage, «Defining an Improvement Strategy» (DIS), is to identify the objectives and requirements of the proposed improvement. This stage is part of the first phase of the ITIL cycle, «Service Strategy», comprising the moment when all the requirements and business needs must be considered. This proposal identifies the following key dimensions referenced by the respondents, namely, (a) the identification of leadership for change, (b) the identification of the vision, the definition of commitment and definition of organizational capacities, and (c) the assessment of the current situation and identification of the existing gap.

The second CM stage, «Design of Improvement» (DI), informs the collection of data essential for the design and specification of the transition process required for the implementation of the improvement. This proposal stage correlates two phases of the ITIL life cycle, namely, «Service Design» and «Service Transition». The design must cover all IST in the organization. Here, strategy becomes a structured plan to achieve business objectives. It defines and sets an orientation for the design, development and service management practices, and identifies the principles and methods for converting strategic objectives into portfolios of services. It should be noted that the service design is not limited to new services and processes. It also includes the changes and improvements necessary to increase the value of change and the continuity of the best service levels.

In the «Transition» phase, the service is tested, implemented and the change in the production environment proceeds. This phase provides an orientation for the development and improvement of capacities and introduces new or modified services and processes. It is awkward that the respondents did not assign a relevant score and did not considered that change should be framed in, when previously they considered it relevant to change. The «Consolidation» of the improvement design (IDC) phase allows the validation of all variables designed and thought out. Therefore, the value identified in the DIS stage and built in the DI stage can be obtained. The "Operationalization of Improvement» (IO) integrates the implementation of improvement based on knowledge and consolidated design. 
Put together, having seen the success of the change and the associated gains, the integration of the new state should be celebrated.

\section{CONCLUSION}

Health organizations deal with a diversity and heterogeneity of information to develop and evaluate performance activities in the provision of health care. Bearing in mind the importance of IST for most organizations and the impact of their implementation (Cunha \& Rego, 2002), it is essential to maximize the organizational efficiency and, in the case of health organizations, minimize the negative impact on the provision of care services. The present work focuses on the evaluation of how health managers understand and apply change. The professionals' behavior regarding CM is critical to the success of IST projects and services in HCOs. Some health organizations are unaware of the ITIL methodology which in turn informs CM. The knowledge of this methodology according to Cartlidge, et al., (2007) proves to be essential to facilitate the IST service changes and the involvement of their professionals.

IST services dictate a dynamic and versatile management approach to respond to organizational change. The use of ITIL methodology makes it possible to consolidate the role of IST in supporting decision-making via the provision of a set of services and processes supported by technologies. The management of Portuguese public hospitals, as top management professionals, reveal strategic characteristics of concern with the impacts of change and application of good practice methodologies and the data from the surveys. Considering the results obtained, it is possible to observe that there is a strong concern in guaranteeing a strategic policy for managing change within the IST. That is possible through applying good practices, as validated by $53.8 \%$ of the answers of the organization managers who adopt the practices associated with ITIL.

Hospitals managers perceive that IST allows them to build a strategic and development path and this is evident when $92.3 \%$ of professionals consider that ITIL has associated processes of change. Based on the findings, it is also evident that CM begins in the "Service Design" and it remains important in other phases or stages such as «Improvement» or «Continuous Service». However, it should also be noted that the "Service Transition" phase does not assume the expected importance. At the organizational level, the adoption of PDCA + SDCA cycle allows IST managers to define which services are essential to improve the efficiency of the business to achieve its results. This methodology makes business processes more efficient, guaranteeing the quality of service delivery, process optimization, productivity, customer satisfaction, and growth, thus contributing to the organization's stability and survival. The study results show that, in general, Portuguese hospitals' managers should consolidate their CM practices, methods and techniques to generate beneficial economic and organizational values.

Many other potential impacts may also be studied, such as the computational costs of change, efficiency gains, productivity, and more; however, these will be topics to be included for future research directions.

\section{ACKNOWLEDGEMENTS}

The authors would like to thank to Polytechnic Institute of Setúbal (Portugal) for the support given to this research work. 


\section{REFERENCES}

Agyeman-Budu, E., \& Welvaert, F. (2006). Investing in health care management: A way to explore the future value outlook of the health care sector. Corporate Governance, 6(4), 431-439. doi:10.1108/14720700610689540

Alves, A. (2014). Innovation in Hospital Management - 40 years of April in healthcare. Almedina. (in Portuguese)

Ammenwerth, E., Iller, C., \& Mahler, C. (2006). IT-adoption and the interaction of task, technology and individuals: A fit framework and a case study. BMC Medical Informatics and Decision Making, 6(1), 3. doi:10.1186/1472-6947-6-3 PMID:16401336

Applebaum, S., \& Wohl, L. (2000). Transformation or change: Some prescriptions for health care organizations. Managing Service Quality, 10(5), 279-298. doi:10.1108/09604520010345768

Axelos. (n.d.). https://www.axelos.com/

Asad Mir, F., Rezania, D., \& Baker, R. (2020). Managing Change in Pluralistic Organizations: The Role of Normative Accountability Assumptions. Journal of Change Management, 20(2), 123-145. doi:10.1080/1469 7017.2020.1720776

Balogun, J., \& Haley, V. (2004). Exploring Strategic Change. Prenctice-Hall.

Bériot, D. (1997). Change in the Enterprise - a systemic approach. From the Microscope to the Macroscope. Society and Organization Collection. (in Portuguese)

Camara, P. (2005). Humanator: Human Resources and Business Success (6th ed.). Don Quixote publishing. (in Portuguese)

Campbell, R. (2008). Change management in health care. The Health Care Manager, 27(1), 23-39. doi:10.1097/01. HCM.0000285028.79762.a1 PMID:18510142

Cartlidge, A., Hanna, A., Rudd, C., Macfarlane, I., Windebank, J., \& Rance, S. (2007). An Introductory overview of ITIL. The UK Chapter of the itSMF.

Casella, P. (2009). The hospital as a structure - Hospital governance. Alfragide, 289-302. (in Portuguese)

Chiavenato, I. (2010). Administration of the new times (2nd ed.). Elsevier. (in Portuguese)

Church, A., Siegal, W., Javitch, M., Waclawski, J., \& Burke, W. (1996). Managing organizational change: What you don't know might hurt you. Career Development International, 1(2), 25-30. doi:10.1108/13620439610114315

Cox, J. W., \& Hassard, J. (2010). Discursive recontextualization in a public health setting. The Journal of Applied Behavioral Science, 46(1), 119-145. doi:10.1177/0021886309357443

Craft, L., Warnock, E., \& Heltai, M. G. (2013). The Change Management Body of Knowledge. Capturing the Maximum Value Possible from Projects.

Cunha, M., \& Rego, A. (2002). The two faces of organizational change: planned and emerging. FEUNL Working Paper Series, 407. (in Portuguese)

DGS. (2004). National healthplan 2004-2010. Lisbon: Directorate-General of Health, Ministry of Health.

DGS. (2012). National Health Plan 2012-2016. http://pns.dgs.pt/pns-2012-January 2016/ (in Portuguese)

Drucker, P. (1993). The New Realities. Harper \& Row.

Fernandes, A. (2014). The public-private combination - 40 years of April in healthcare. Almedina. (in Portuguese)

Galpin, T. (2000). The Human Side of Change: A Practical Guide to Organizational Change. Silabo Publishing. (in Portuguese)

Galpin, T. J. (1996). The Human Side of Change: A Practical Guide to Organization Redesign. Academic Press.

Garrido, M., Kristensen, F., Nielsen, C., \& Busse, R. (2008). Health technology assessment and health policymaking in Europe. In European Observatory on Health Systems and Policies Observatory. Studies Series No 14. World Health Organization. 
Geada, N. (2019). Change Management in the Digital Economy: Model Proposal. International Journal of Innovation in the Digital Economy, 11(3).

Geada, N., \& Anunciação, P. (2019). Change Management Projects in Information Systems: The impact of the Methodology Information Information Technology Infraestructure Library (ITIL). In HandBook of Research on Emerging Technologies for Effective Project Management. IGI Global Publication.

Gersick, C. (2020). Reflections on Revolutionary Change. Journal of Change Management, 20(1), 7-23. doi: $10.1080 / 14697017.2019 .1586362$

Golden, B. (2006). Change: Transforming health organisations. Healthcare Quarterly, 10(sp), 10-19. doi:10.12927/hcq..18490 PMID:17163111

Harfouche, A. (2008). Hospitals transformed into companies - Analysis of the impact on efficiency: A comparative study. Higher Institute of Social and Political Sciences. (in Portuguese)

Hernandez, J., \& Caldas, M. (2001). Resistance to change: a critical review. Business Administration Journal. (in Portuguese)

Iles, V., \& Sutherland, K. (2001). Organisational Change: A Review for Health Care Managers, Professionals and Researchers. NHS Service Delivery and Organisation R\&D.

Kezar, A. (2001). Theories and models of organizational change. SHE ERIC Higher Education Report, Part 4.

Klosterboer, L. (2011). ITIL Capacity Management. International Business Machines Corporation.

Kotter, J. (1995). Why Transformation Efforts Fail. Harvard Business Review.

Kotter, J. (1996). Leading Change. Harvard Business School Press.

Lapoite, L., \& Rivard, S. (2006). Gettinf physicians to accept new information technology: Insights from case studies. Canadian Medical Association Journal.

Lewin, K. (1947). Frontiers in Group Dynamics. Human Relations.

Lewin, K. (1951). Field Theory in Social Science. Harper \& Row.

Lewis, I. (1985). Social Anthropology in Perspective. Cambridge University Press.

Lippit, R., Watson, J., \& Westley, B. (1958). The Dynamics of Planned Change. Harcourt, Brace \& World.

Luecke, R. (2003). Managing Change and Transition. Harvard Business School Press.

McAuliffe, E., \& Vaerenbergh, C. (2006). Guiding Change in the Irish Health System. Health Service Executive.

Mento, A., Jones, R., \& Dirndorfer, W. (2002). A change management process: Grounded in both theory and practice. Journal of Change Management, 3(1), 3. doi:10.1080/714042520

Mikkola, L., \& Stormi, I. (2020). Change Talk in Hospital Management Groups. Journal of Change Management, 1-20. Advance online publication. doi:10.1080/14697017.2020.1775679

Oliveira, A. \& Anunciação, P. F. (2019). Information Systems Governance. Results of surveys of Large companies and Public Administration in Portugal, Information Systems Governance - Concepts, best pratices and case studies. Chiado Publishing. (in Portuguese)

Patterson, K. \& Wigham, G. (2019). Management of Change - what does a 'good' system look like? Loss Prevention Bulletin, 267, 7-10.

Pettigrew, A., \& Whipp, R. (1991). Managing Change for Competitive Success. Blackwell.

Porras, J., \& Robertson, P. (1992). Handbook of Industrial and Organisational Psychology. Consulting Psychologists Press.

Rance, S., Rudd, C., Lacy, S., \& Hanna, A. (2011). ITIL Service Management - (2011 Edition). TSO - The Stationery Office. 
Rapoport, R. (1970). Three Dilemmas in Action Research. Human Relations, 23(6), 499-513. doi:10.1177/001872677002300601

Rego, G., \& Nunes, R. (2010). Health Management. Prata \& Rodrigues. (in Portuguese)

Saltman, R. B., \& Duran, A. (2016). Governance, government, and the search for new provider models. International Journal of Health Policy and Management, 5(1), 33-42. doi:10.15171/ijhpm.2015.198 PMID:26673647

Thurlow, A., \& Mills, J. H. (2009). Change, talk, and sense making. Journal of Organizational Change Management, 22(5), 459-479. doi:10.1108/09534810910983442

Todnem, R. (2005). Organisational change management: A critical review. Journal of Change Management, 5(4), 369-380. doi:10.1080/14697010500359250

Todnem, R. (2005). Organizational Change Management: A Critical Review. Journal of Change, 369-380.

Turner, D.-M., Hallencreutz, J., \& Haley, H. (2009). Leveraging the Value of an Organizational Change. The International Journal of Knowledge, Culture \& Change Management.

Van de Ven, A., \& Poole, M. (1995). Explaining developement and change in organizations. Academy of Management Review, 20(3), 510-540. doi:10.5465/amr.1995.9508080329

Vaz, A. (2010). Portuguese public hospitals. 30 Years of National Health Service: a commented path. Almedina (in Portuguese).

Walsham, G. (1993). Interpreting Information Systems in Organizations. Wiley.

Weick, K. (2000). Emergent change as a universal in organizations, Breaking the code of change. Harvard Business School Press.

Weick, K., \& Quinn, R. (1999). Organizational Change and Development. Annual Revision Psychology. 